\title{
Bilateral anterior compartment syndrome secondary to psychogenic polydipsia
}

\author{
William Hughes $^{1} \cdot$ Neill McCormack ${ }^{1} \cdot$ Claire Cattigan ${ }^{1} \cdot$ Damon Thomas $^{2} \cdot$ Stephen J. Goldie ${ }^{2,3,4}$
}

Received: 24 October 2021 / Accepted: 8 January 2022 / Published online: 27 January 2022

(c) The Author(s) 2022

\begin{abstract}
Compartment syndrome is a surgical emergency requiring urgent release of the muscular compartments to prevent ischaemia and tissue death. Unusual presentation patterns or aetiological factors may be confusing, delaying the diagnosis and prompt management. We report a rare case of bilateral anterior compartment syndrome, secondary to psychogenic polydipsia. Compartment pressures were measured using a manometer. The patient was expedited to theatre for exploration. A literature review was performed to search for similar cases. In our case, a 42-year-old male presented confused and agitated with bilateral lower limb pain unresponsive to opiates. He had a past medical history of schizophrenia with psychogenic polydipsia, consuming $10 \mathrm{~L}$ of cola soft drink per day prior to presentation. Blood tests showed sodium of $112 \mathrm{mmol} / \mathrm{L}$ and a peak creatinine kinase of 13,417 U/L. On examination, he had tense and swollen bilateral anterior legs; posterior calves were soft. Left and right anterior compartment pressures were measured at $60 \mathrm{mmHg}$ and $90 \mathrm{mmHg}$ respectively (normal limit $<30 \mathrm{mmHg}$ ). At operation, bilateral fasciotomies of the anterior compartments were performed and bulging muscles were found. Reported cases similar to this resulted in permanent disability due to delays in recognising the diagnosis. Follow-up of this patient showed return of normal sensation and movement of the muscles of the anterior compartment. Hyponatraemia as a result of psychogenic polydipsia is well recognised, but isolated anterior compartment syndrome is a rare complication of hyponatraemia. This case report highlights the need to consider non-traumatic causes of compartment syndrome.
\end{abstract}

Level of evidence: Level V, Diagnostic study

Keywords Compartment syndrome $\cdot$ Fasciotomy $\cdot$ Psychogenic polydipsia $\cdot$ Schizophrenia

\section{Introduction}

Compartment syndrome in the limbs is a surgical emergency requiring urgent release of the muscular compartments to prevent ischaemia and tissue death. Commonly, it develops following accidental trauma or as a sequelae of surgery in the limb. Unusual presentation patterns or aetiological

Stephen J. Goldie

Stephen_goldie@hotmail.com

1 Intensive Care Unit, University Hospital Geelong, Barwon Health, Geelong, Australia

2 Department of Plastic Surgery, University Hospital Geelong, Barwon Health, Geelong, Australia

3 Department of Surgery, Central Clinical School, Monash University, Melbourne, Australia

4 College of Medicine and Public Health, Flinders University, Adelaide, Australia factors may be confusing, delaying the diagnosis and prompt management. We report a rare case of bilateral anterior compartment syndrome, secondary to psychogenic polydipsia.

\section{Case report}

A 42-year-old male presented confused and agitated with bilateral lower limb pain unresponsive to opiates. He had a past medical history of schizophrenia with psychogenic polydipsia, consuming over $10 \mathrm{~L}$ of diet cola soft drink per day prior to presentation. Blood tests showed sodium of $112 \mathrm{mmol} / \mathrm{L}$ and a peak creatinine kinase of $13417 \mathrm{U} / \mathrm{L}$. On examination he had tense and swollen bilateral anterior legs; posterior calves were soft. Compartment pressures were measured using a manometer. Left and right anterior compartment pressures were measured at $60 \mathrm{mmHg}$ and $90 \mathrm{mmHg}$ respectively (normal limit $<30 \mathrm{mmHg}$ ). Posterior 
compartments measured within the normal range bilaterally. The patient was expedited to theatre for exploration. At operation, bilateral fasciotomies of the anterior compartments were performed, and bulging muscles were found. The posterior compartments were not released due to the normal examination findings. In theatre, a urinary catheter was passed to allow monitoring of the patient's urine output given the high risk of rhabdomyolysis, and the patient was commenced on intravenous fluids to prevent renal failure and treat the hyponatraemia. The patient returned to theatre the following day where it was noted although the muscles were still grossly swollen and bulging from the anterior compartment, but they did appear alive and well perfused. Further $72 \mathrm{~h}$ later, the patient had stabilised medically and returned to theatre for split skin graft coverage of the wounds. A literature review using OVID Medline and PubMed was performed to search for similar cases (Fig. 1).

\section{Discussion}

Compartment syndrome affecting all the compartments of a limb is relatively common and may be managed by a variety of surgical teams including plastic, orthopaedic, vascular or general surgeons. Compartment syndrome isolated to the anterior compartment and from a medically induced aetiology is very rare. Our review found only five published cases [1-5]. Four cases were secondary to psychogenic polydipsia, and one case attributed to severe primary hypothyroidism and adrenal insufficiency. Patients may present with unilateral or bilaterally affected legs. The severe hyponatraemia may also induce seizures because of cerebral oedema [2] or be fatal because of the brain injury or cardiac arrest from hyperkalaemia secondary to rhabdomyolysis and renal failure [3].

Traditional surgical teaching holds that where there is sufficient clinical suspicion of compartment syndrome, then the patient should be expedited to theatre for surgical fasciotomies without delaying to formally measure compartment pressures. However, given the unusual presentation in this case, it was deemed sensible to record pressures formally. The skin is cleaned, and some local anaesthetic infiltrated under the skin. Using either a commercially available handheld device or a needle, syringe and giving set rigged up to a manometer (pressure monitor), the needle is passed perpendicular through the skin and into the muscle compartment. Exact level of pressure elevation that causes cell death is unclear. It was previously thought that pressure $>30 \mathrm{mmHg}$ was toxic although the "delta pressure" may be better predictor than absolute pressure:

$\Delta$ Pressure $=[$ DiastolicPressure $]-[$ CompartmentPressure $]$ $\Delta$ Pressure $<30 \mathrm{mmHgissuggestiveof} \mathrm{compartmentsyndrome.}$

All of the published cases similar to the one described in this case report resulted in permanent disability due to delays in recognising the diagnosis. Drop foot and loss
Fig. 1 A Left leg fasciectomy wound showing muscle bulging from the anterior compartment. B Right leg fasciectomy wound showing muscle bulging from the anterior compartment. $\mathbf{C}$ Right leg fasciectomy wound with meshed split thickness skin graft reconstruction. D Right leg fasciectomy wound with meshed split thickness skin graft reconstruction, showing residual muscle bulging
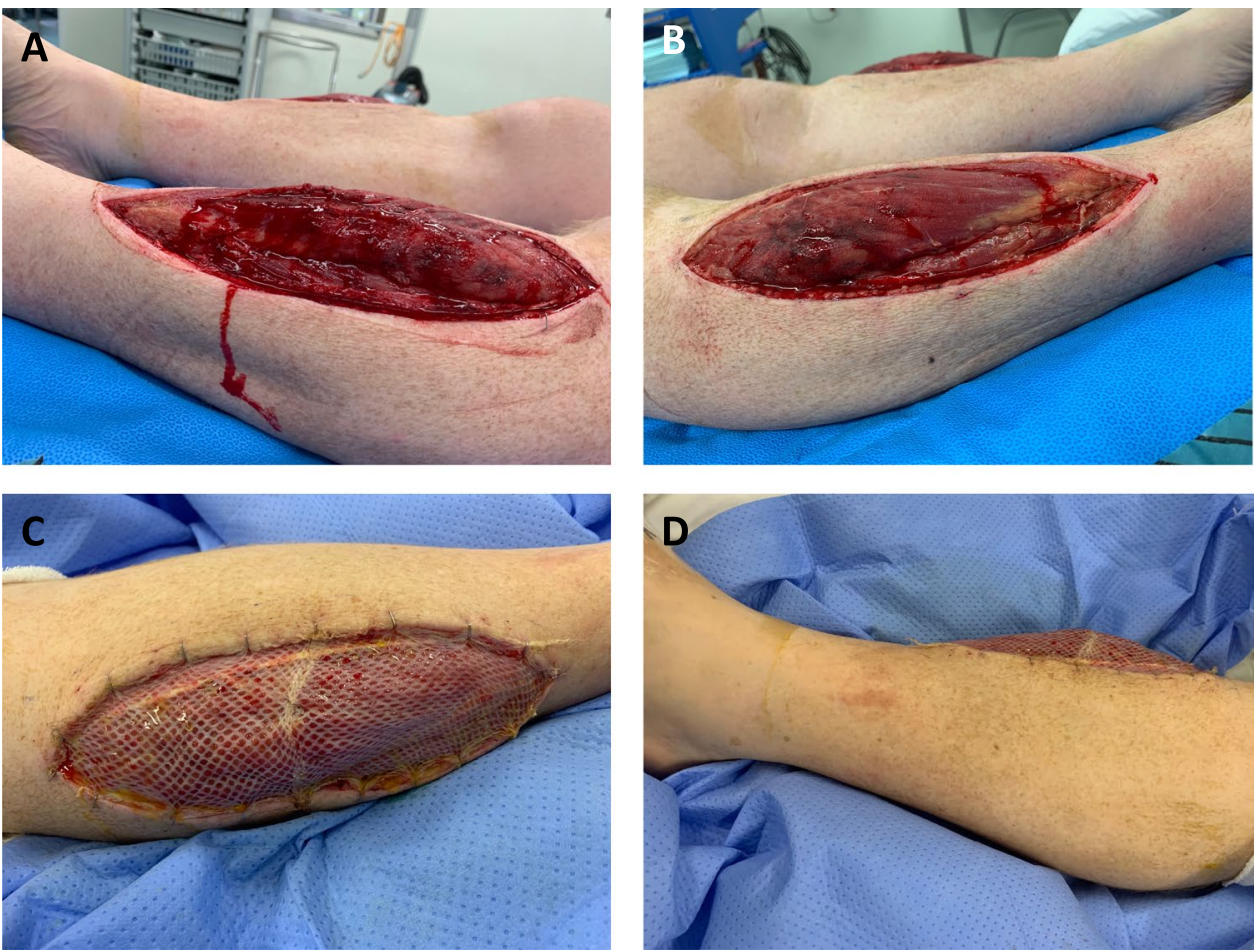
of sensation in the dorsal foot is the likely outcome for a patient with delayed release of the anterior compartment $[1,3,4]$. This is due to necrosis of the muscles in the anterior compartment and/or compression of the deep peroneal nerve as it passes through the compartment, supplying the muscles before giving sensation to the 1st webspace on the dorsum of the foot. Follow-up of the patient in this case report showed return of normal sensation of the foot and movement of the muscles of the anterior compartment, presumably due to the early diagnosis and prompt surgical management.

\section{Conclusion}

Hyponatraemia as a result of psychogenic polydipsia is well recognised, but isolated anterior compartment syndrome is a rare complication of hyponatraemia. This case report highlights the need to consider non-traumatic causes of compartment syndrome.

Funding Open Access funding enabled and organized by CAUL and its Member Institutions.

\section{Declarations}

Ethical approval All procedures performed in studies involving human participants were in accordance with the ethical standards of the institutional and/or national research committee and with the 1964 Helsinki Declaration and its later amendments or comparable ethical standards. This case report has been registered with Barwon Health HREC. No ethical approval was required for this case report.

Informed consent The patient has given informed consent to the publication of images and data.
Conflict of interest William Hughes, Neill McCormack, Claire Cattigan, Damon Thomas, and Stephen J. Goldie declare no conflict of interest.

Open Access This article is licensed under a Creative Commons Attribution 4.0 International License, which permits use, sharing, adaptation, distribution and reproduction in any medium or format, as long as you give appropriate credit to the original author(s) and the source, provide a link to the Creative Commons licence, and indicate if changes were made. The images or other third party material in this article are included in the article's Creative Commons licence, unless indicated otherwise in a credit line to the material. If material is not included in the article's Creative Commons licence and your intended use is not permitted by statutory regulation or exceeds the permitted use, you will need to obtain permission directly from the copyright holder. To view a copy of this licence, visit http://creativecommons.org/licenses/by/4.0/.

\section{References}

1. Dubin I, Gelber M, Schattner A (2016) Rare times rare: The hyponatremia, rhabdomyolysis, anterior compartment syndrome sequence. JRSM Open 3(7):2054270416629326

2. Zaman MO, Greenberg E, Khan QA, Jan N, Bashir S, Mojadidi MK (2016) Unilateral acute anterior compartment syndrome from correction of psychogenic polydipsia-induced hyponatremia. Am J Med 129:e285-e286

3. Maiocchi L, Bernardi E (2012) Acute anterior compartment syndrome associated with psychogenic polydipsia. Australas Psychiatry 20:159-161

4. Ulstrup A, Ugleholdt R, Rasmussen JV (2015) Fulminant crural compartment syndrome preceded by psychogenic polydipsia. BMJ Case Rep 2015(14):bcr2014208603

5. Muir P, Choe MS, Croxson MS (2012) Rapid development of anterotibial compartment syndrome and rhabdomyolysis in a patient with primary hypothyroidism and adrenal insufficiency. Thyroid 22(6):651-653

Publisher's note Springer Nature remains neutral with regard to jurisdictional claims in published maps and institutional affiliations. 